\title{
Effect of Temperature on the Tensile Properties of High-Purity Nickel
}

\author{
${ }^{*}$ William D. Jenkins and Thomas G. Digges
}

\begin{abstract}
Tension tests were made at temperatures ranging from $-320^{\circ}$ to $1,500^{\circ} \mathrm{F}$ on highpurity nickel in the annealed condition. Exceptions to the usual trend exhibited by metals of decreasing strength and increasing ductility with increasing test temperature were observed and discussed. Strain aging occurred in specimens tested in the temperature range of about $80^{\circ}$ to $300^{\circ} \mathrm{F}$, but recrystallization and recovery predominated in specimens fractured at $1,200^{\circ}$ and $1,500^{\circ} \mathrm{F}$.
\end{abstract}

\section{Introduction}

The tests described in this paper are a part of a comprehensive investigation to evaluate the rheological behavior, tensile and creep properties of highpurity nickel, high-purity copper, and alloys of these two metals. The relatively low range in temperature at which creep may occur in these metals, the unlimited solid solubility of the two metals in each other, the availability of commercial metals of very highpurity, and the wide industrial applications of both the metals and alloys make this binary system an attractive one for use in this study.

The results of creep tests at $110^{\circ}, 250^{\circ}$, and $300^{\circ} \mathrm{F}$ on high-purity (OFHC) copper and of short-time tensile tests at temperatures ranging from $-320^{\circ}$ to $+212^{\circ} \mathrm{F}$ on the copper, nickel, and copper-nickel alloys initially as annealed were presented in previous publications. ${ }^{1,2,3}$ Additional short-time tensile tests were made at temperatures ranging from room to $1,500^{\circ} \mathrm{F}$ on the same lot of annealed high-purity nickel, ${ }^{4}$ and the results of the present and previous tests on the nickel are contained in the present paper.

\section{Material and Test Procedures}

The specimens used in making the tension tests were prepared from two bars from the same heat containing 99.85 percent of $\mathrm{Ni}, 0.009$ percent of $\mathrm{Cu}$, 0.04 percent of $\mathrm{Fe}, 0.03$ percent of $\mathrm{Mn}, 0.11$ percent of Si, 0.007 percent of $\mathrm{C}, 0.002$ percent of $\mathrm{S}, 0.002$ percent of $\mathrm{O}, 0.001$ percent of $\mathrm{N}$, and 0.002 percent of $\mathrm{H}$ as determined by chemical, spectrochemical, and vacuum fusion analyses. The bars were hot-worked to $11 / 16$-in. diameter and subsequently annealed during manufacture for an average grain diameter of $0.045 \mathrm{~mm}$.

In one series of tensile tests made at temperatures ranging from room temperature to $1,500^{\circ} \mathrm{F}$, the specimens were $6 \frac{1}{2}$ in. long, with a reduced section of 0.505 -in. diameter for a 2 -in. gage length. The

1 W. D. Jenkins and T. G. Digges, Creep of high-purity copper, J. Research NBS 45, $153(1950)$ RP2121.

2 W. D. Jenkins and T. G. Digges, Creep of annealed and cold-drawn highpurity copper, J. Research NBS 47, 272 (1951) RP2254.

${ }_{3}$ G. W. Geil and N. L. Carwile, Tensile properties of copper, nickel and some copper-nickel alloys at low temperatures, NBS symposium on mechanical properties of metals at low temperatures, NBS Circular $520(1952)$

4 The high-purity nickel was prepared specially for the National Bureau of Standards by the International Nickel Co. through the cooperation of W. A. Mudge. shoulder fillets were of $1 / 4$ in. radius, and the ends were machined with $3 / 4 \mathrm{in}$. $\times 10$ threads. The reduced section of each specimen was finished by grinding and then polishing in the axial direction, using No. 400 Aloxite metallographic polishing paper. Each specimen was heated in an electric furnace to the desired temperature (above room) and held at temperature for a minimum of 3 hours before being tested. The specimen was maintained within $\pm 3^{\circ} \mathrm{F}$ of the desired temperature, and the gradient over the gage length did not exceed $5^{\circ} \overrightarrow{\mathrm{F}}$ during the period of testing. The specimens were tested in a hydraulic type machine (15,000-lb range) with the specimen and holders occupying about $3 \mathrm{ft}$ between two self-alining grips. The movement of the head of the machine during the testing was recorded by means of a stress-strain recorder of the Templin type. The loading was controlled to produce a rate of extension of about 1 percent per minute; a rate of the same order of magnitude as that used in the previous series of tests. All the specimens used in the above series of tests were prepared from the same bar, but this was not the same bar as that used for the specimens tested at subzero temperatures.

The preparation of the specimens and the testing procedure used in other series of tests made at temperatures ranging from $-320^{\circ}$ to $+212^{\circ} \mathrm{F}$ are described in detail in a previous report (see footnote ${ }^{3}$ ). Essentially, the specimens were 0.505 in. in diameter, with a 2 -in. gage length, and they were fully immersed during the testing in tension at a controlled rate of loading to produce a contraction of approximately 1-percent reduction of area per minute. The change in minimum diameter of the specimen during the testing was measured by a special reduction of area gage; for the tests made at room temperature no liquid bath was used, and the diameter measurements were made with a micrometer. All the tensile specimens used in this series were prepared from the same bar.

One specimen was tested in tension at each selected temperature, except that two specimens (one of each series) were tested at room temperature and two at $212^{\circ} \mathrm{F}$.

Rockwell B hardness (100-kg load, 1/16-in.-diameter ball) tests were made at room temperature on the 
specimens prepared from the annealed bars and on the tensile specimens after fracturing at temperatures ranging from $88^{\circ}$ to $1,500^{\circ} \mathrm{F}$. Two flats, $180^{\circ}$ apart, were prepared parallel to the longitudinal axis of the fractured specimens, and the Rockwell readings were made at various points along the center line of these flats; the specimens were about 0.2 in. thick. The diameters of the specimen at the points of indentation were accurately determined to correlate the degree of plastic deformation with the hardness values.

The usual procedures were followed in preparing specimens by mechanical methods for metallography and in carrying out the metallographic examination.

\section{Results and Discussion}

\subsection{Stress-Strain Curves}

The stress-strain record obtained in testing specimens in tension at temperatures ranging from $88^{\circ}$ to $1,500^{\circ} \mathrm{F}$ is given in figure 1 . No definite yield point (drop of beam) is evident in any of these curves; furthermore, no yield point was observed in any of the specimens tested at subzero temperatures. Although a comparison of the relative height and width of these curves indicates the effects of temperature on the stress and ductility, respectively, of the initially annealed high-purity nickel, the influence of temperature on these properties is more clearly shown by the results summarized in figures 2 to 10 .

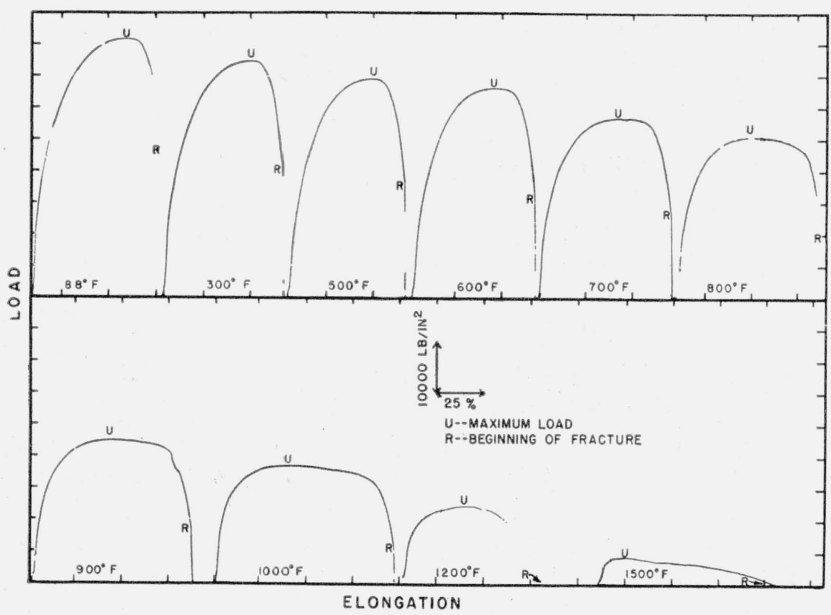

FIgURE 1. Automatic stress-strain records of high-purity nickel specimens tested in tension at different temperatures.



FIGURE 2. Influence of temperature on the yield strength, tensile strength, and true stress at maximum load of highpurity nickel.

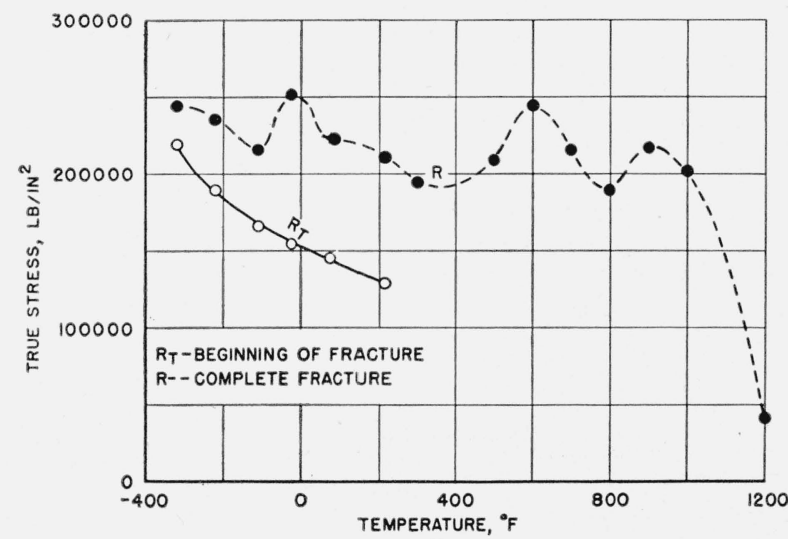

Figure 3. Influence of temperature on the true stresses at the beginning and at complete fracture of high-purity nickel specimens tested in tension. 


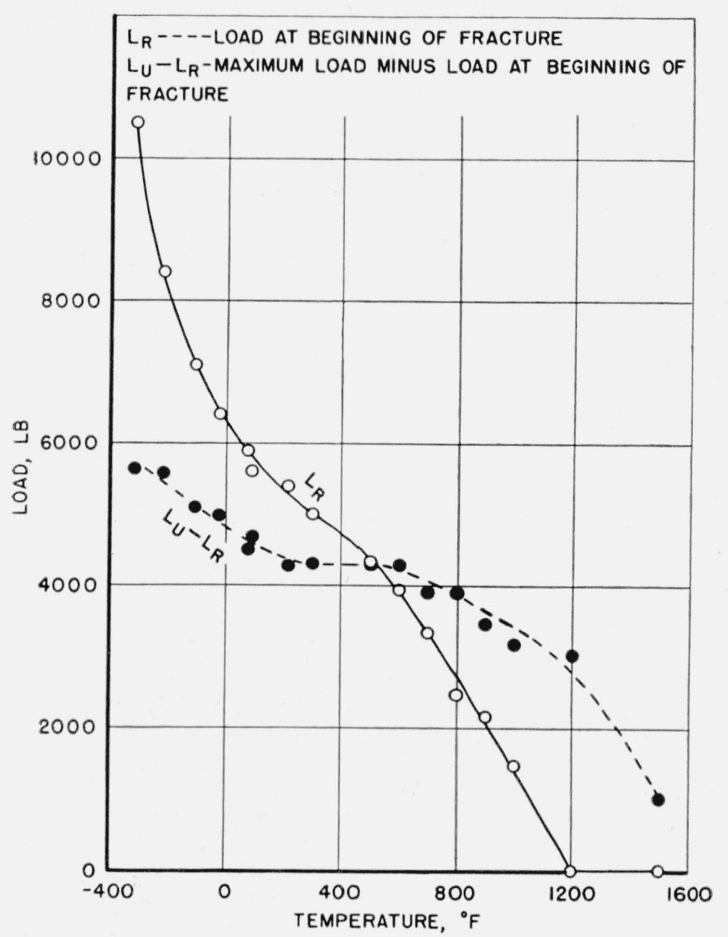

FIGURE 4. Effect of temperature on the loads at fracture and loads corresponding to the difference between the maximum load and the load at fracture.

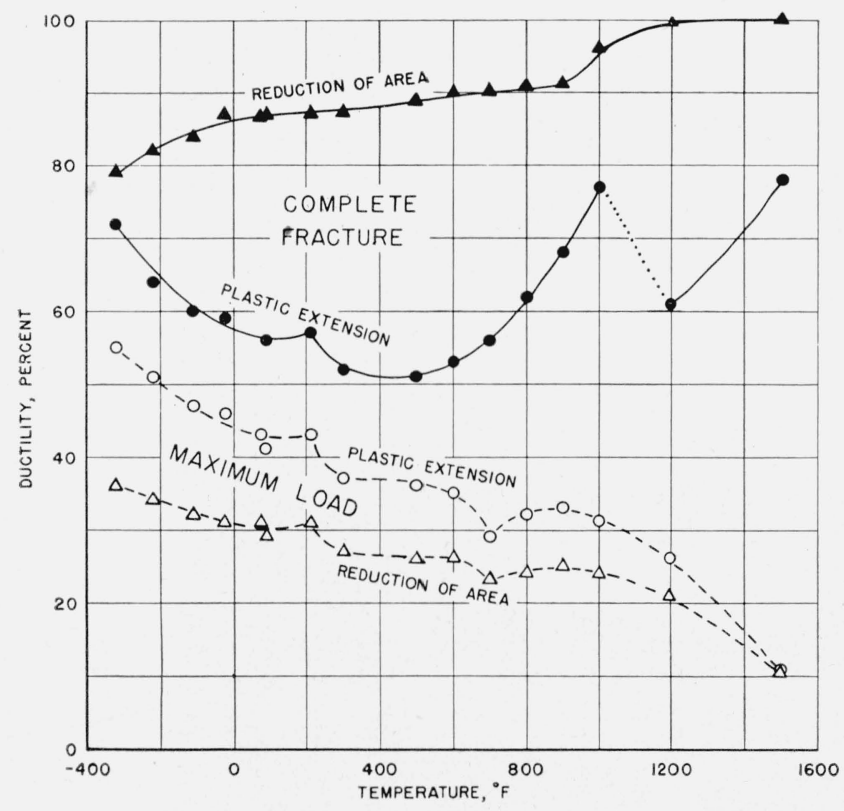

Figure 5. Relation of temperature to the ductility of highpurity nickel specimens fractured in tension.

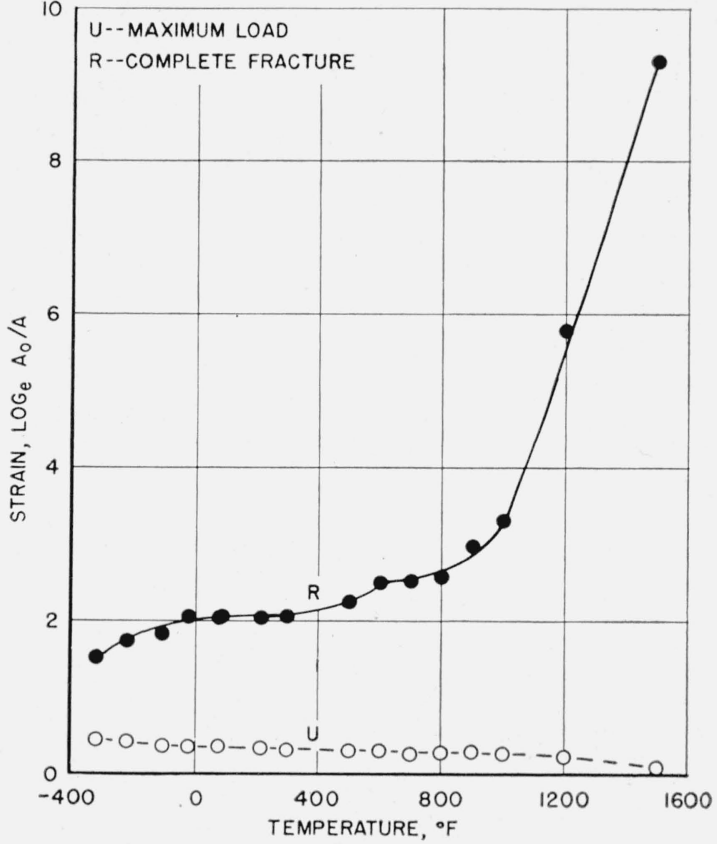

FIGURE 6. Effect of temperature on the true strain at maximum load and at fracture of high-purity nickel specimens tested in tension.

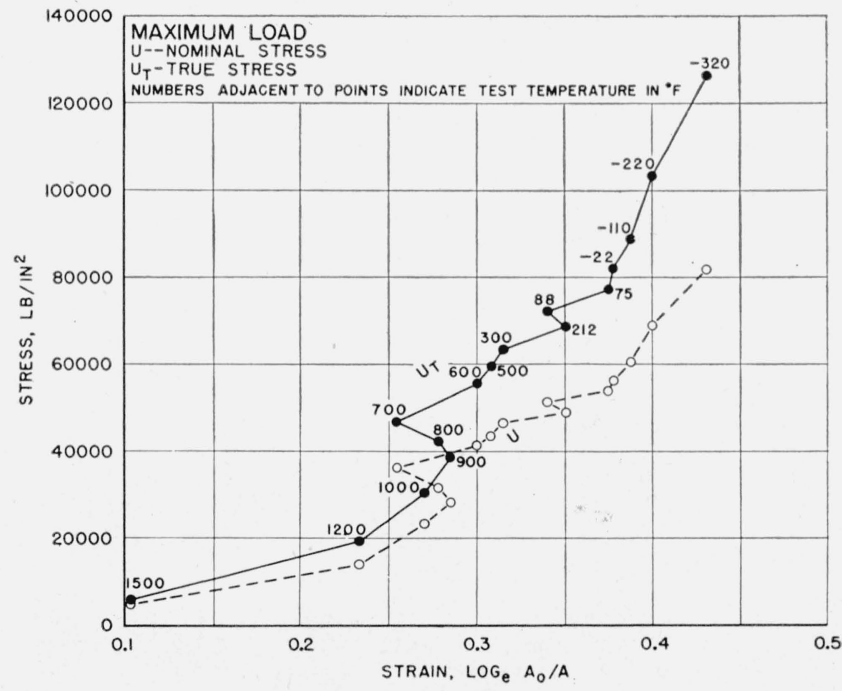

Figure 7. Relation of the nominal and of the true stresses at maximum load to true strain of high-purity nickel specimens fractured in tension at different temperatures. 


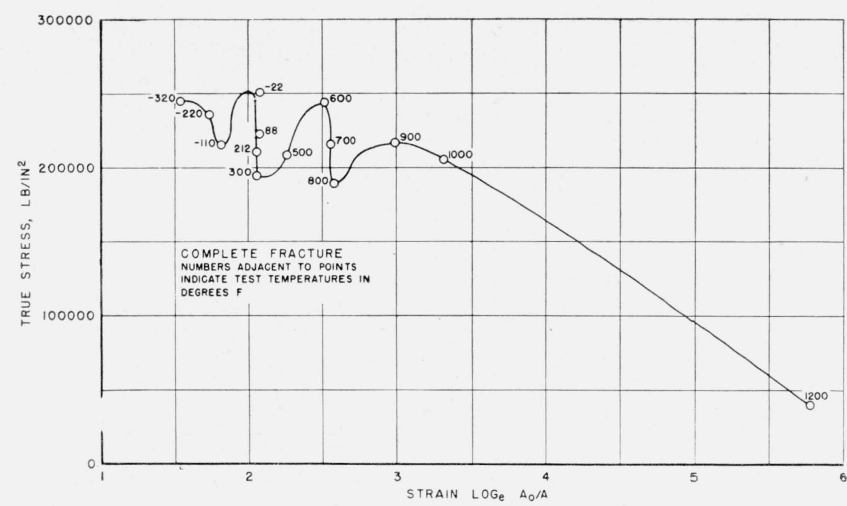

FIGURE 8. Relation of true stress at complete fracture to true strain of high-purity nickel specimens tested in tension at different temperatures.

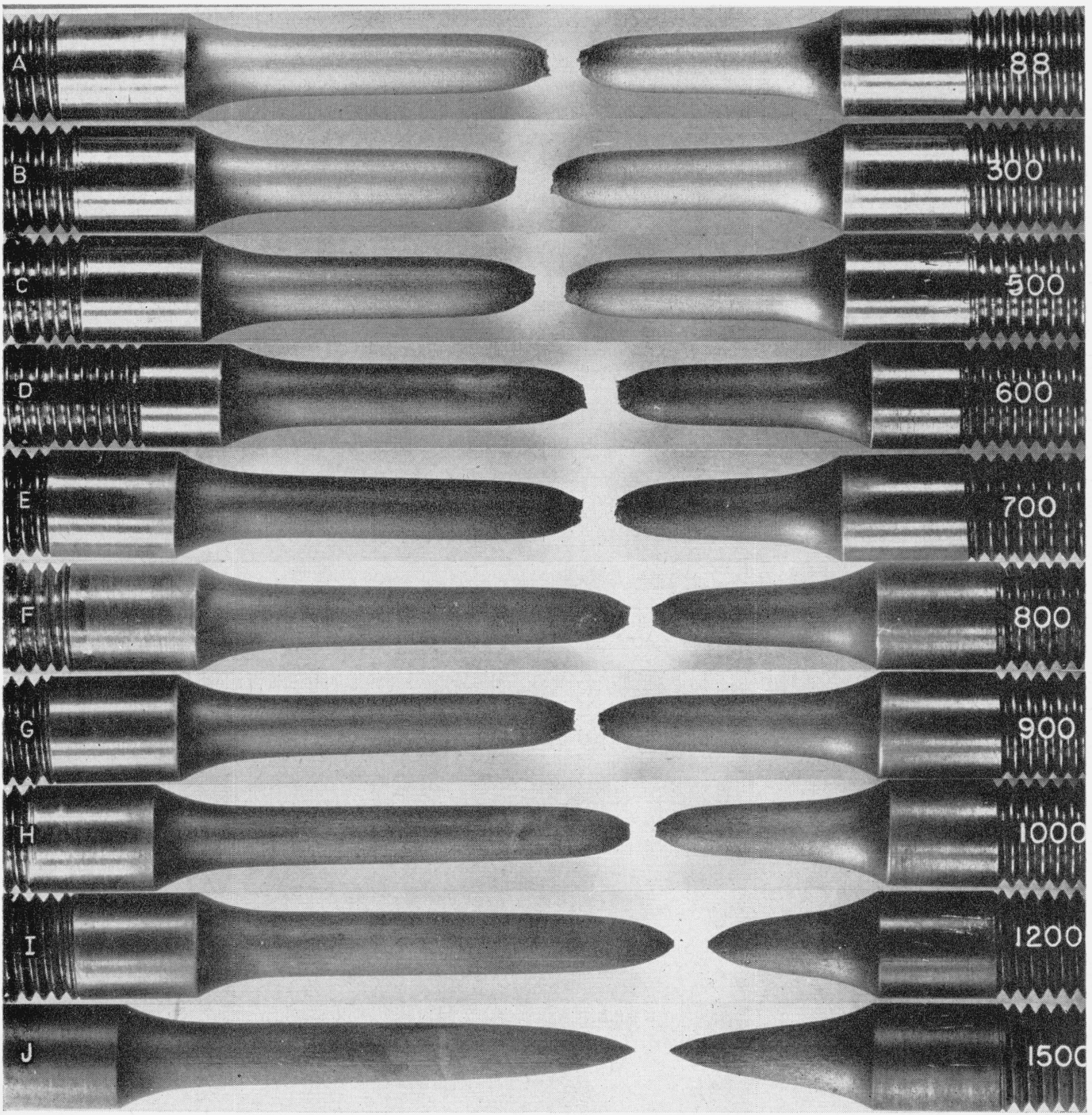

FIGURE 9. High-purity nickel specimens fractured in tension at different temperatures. $X .75$. A, $88^{\circ}$ F; B, $300^{\circ}$ F; C, $500^{\circ}$ F; D, $600^{\circ}$ F; E, $700^{\circ}$ F; F, $800^{\circ}$ F; G, $900^{\circ}$ F; H, $1,000^{\circ}$ F; I, $1,200^{\circ}$ F; J, $1,500^{\circ}$ F. 

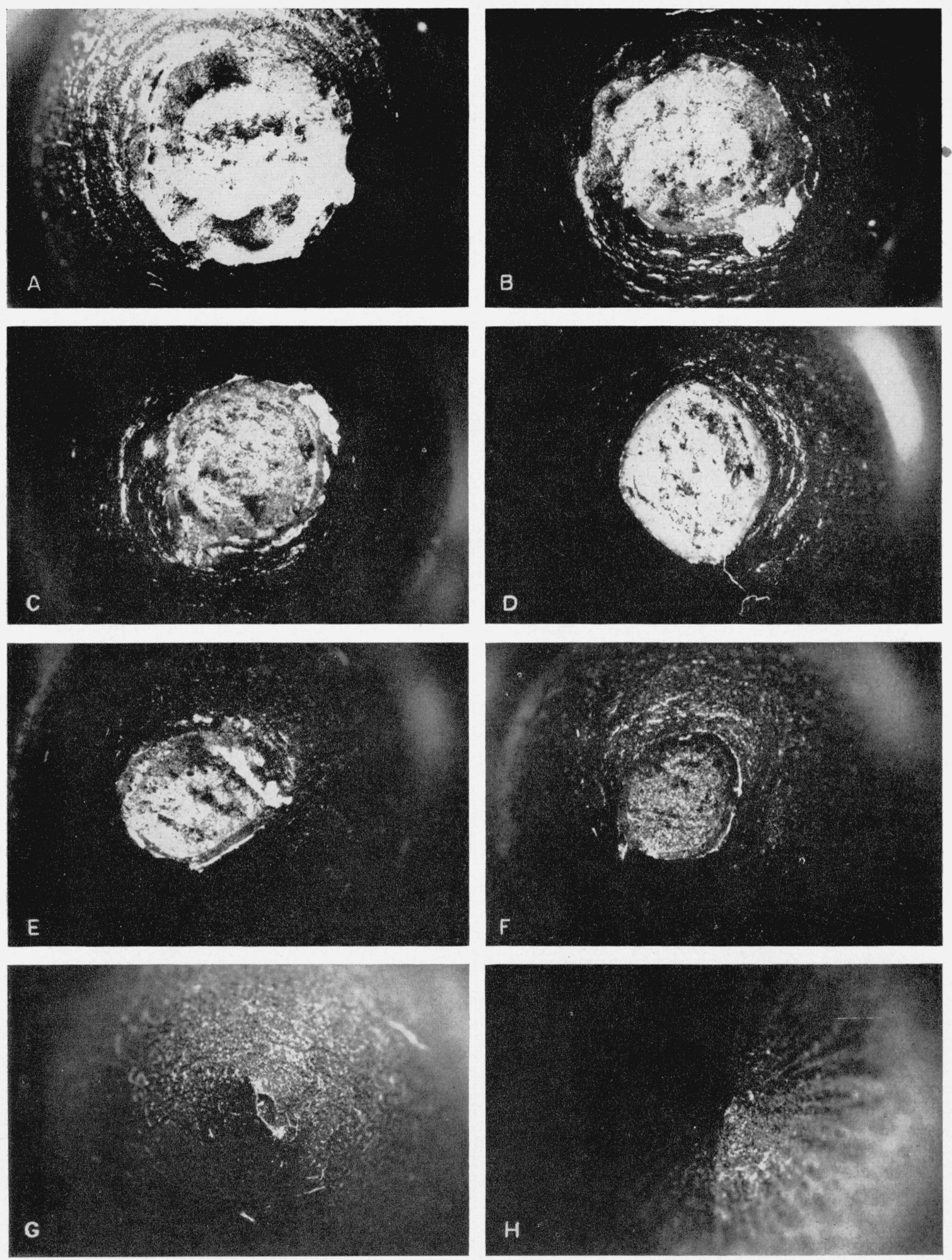

FIGURE 10. Fractured cross sections of high-purity nickel specimens tested in tension at different temperatures. $\times 7$.

A, $88^{\circ} \mathrm{F}$; B, $600^{\circ} \mathrm{F}$; C, $700^{\circ} \mathrm{F}$; D, $800^{\circ} \mathrm{F}$; E, $900^{\circ} \mathrm{F}$; F, $1,000^{\circ} \mathrm{F}$; G, $1,200^{\circ} \mathrm{F} ; \mathrm{H}, 1,500^{\circ} \mathrm{F}$ 


\subsection{Effect of Temperature on Strength}

Both the true stress ${ }^{5}$ and the nominal stress ${ }^{6}$ at maximum load (tensile strength) decreased rapidly as the temperature was increased from $-320^{\circ} \mathrm{F}$ to room and less rapidly with further increase in temperature to about $500^{\circ} \mathrm{F}$ (fig. 2); thereafter, both curves $\left(U_{T}\right.$ and $U$ ) again showed a rapid decrease as the temperature of testing was increased up to $1,500^{\circ} \mathrm{F}$. The general trend for the yield strength (curve $Y$ ) to decrease with an increase in test temperature was reversed when the temperature was within the range of about $80^{\circ}$ to $300^{\circ} \mathrm{F}$. As the temperature was increased from $80^{\circ}$ to about $300^{\circ} \mathrm{F}$, the yield strength-temperature curve sloped upward before again descending with a further increase in temperature. As is to be expected, all three of the curves representing strength-temperature relations approached a common value at the highest test temperature of $1,500^{\circ} \mathrm{F}$.

Reversals are also evident in the slope of the curve of the true stress at complete fracture versus temperature (fig. 3, curve $R$ ). However, the fracture values were within the range of about 250,000 to $190,000 \mathrm{psi}$ for test temperatures from $-320^{\circ}$ to $+1,000^{\circ} \mathrm{F}$. There was a considerable drop in the strength at complete fracture when the test temperature was increased from $1,000^{\circ}$ to $1,200^{\circ} \mathrm{F}$.

The evidence indicates that fracture commenced at or near the longitudinal axis of each specimen (see footnote 1) and then progressed outward to the surface accompanied by appreciable "necking". Due to the "rim effect" the stress at complete fracture, therefore, is considerably higher than the corresponding stress at start of fracture. The rim effect and degree of necking varied with the test temperature (see photographs of fractured specimens given in figs. 9 and 10). The true stress at the beginning of fracture was determined only for temperatures ranging from $-320^{\circ}$ to $+212^{\circ} \mathrm{F}$. The results (fig. 3, curve $R_{T}$ ) show that the strength decreased continuously with an increase in temperature.

The load on the specimen at the beginning of fracture decreased continuously as the temperature increased (fig. 4, curve $L_{R}$ ). It is of interest to note that the load approached zero in value for the specimens tested at $1,200^{\circ}$ and $1,500^{\circ} \mathrm{F}$. This means that each of these two specimens necked down to nearly a point before fracturing (figs. $9, I$ and $J$; fig. 10, $G$ and $H)$. An indication of this tendency to neck, and the accompanying work-hardening and recovery characteristic for the region of plastic deformation extending from that corresponding to the maximum load to the beginning of fracture as affected by temperature is given by the course of the curve $L_{U}-L_{R}$ in figure 4 . Except for the nearly horizontal position of this curve for temperatures within the range from about $212^{\circ}$ to $600^{\circ} \mathrm{F}$, the loads decreased continuously as the temperature increased.

\footnotetext{
${ }^{3}$ The value for true stress is based upon the current cross-sectional area of the specimen.

The value for nominal stress is based upon the original cross-sectional area of the specimen.
}

\subsection{Effect of Temperature on Ductility}

The general trend was for both the plastic extension and reduction of area at maximum load to decrease with increase in temperature (fig. 5). However, definite breaks in the downward trend are evident in the curves as the temperature of testing was increased from about $80^{\circ}$ to $212^{\circ} \mathrm{F}$ and from about $600^{\circ}$ to $700^{\circ} \mathrm{F}$. In the former range the ductility increased with increase in temperature, whereas in the latter this effect was reversed.

The plastic extension at complete fracture-temperature curve also showed a decided break in its downward slope as the temperature increased from $80^{\circ}$ to $212^{\circ} \mathrm{F}$. The extension attained the minimum value at about $500^{\circ} \mathrm{F}$. Thereafter, the extension increased. with test temperature up to about $1,000^{\circ} \mathrm{F}$, dropped markedly as the temperature was increased to $1,200^{\circ}$ $\mathrm{F}$, and then again increased with the temperature. The course of the curve of reduction of area at fracture versus temperature shows that the reduction of area increased relatively rapidly as the temperature increased from about $-320^{\circ}$ to $80^{\circ} \mathrm{F}$ and from $900^{\circ}$ to $1,200^{\circ} \mathrm{F}$. At test temperatures between these two ranges, the reduction of area increased only slightly with an increase in temperature. The reduction of area at $1,200^{\circ}$ and $1,500^{\circ} \mathrm{F}$ attained a value of nearly 100 percent. A noteworthy feature is the high ductility in tension of nickel at test temperatures ranging from $-320^{\circ} \mathrm{F}$ (liquid nitrogen) to $+1,500^{\circ} \mathrm{F}$. The high ductility at low temperatures is characteristic of face-centered cubic metals, such as nickel and copper.

The curve of true strain ${ }^{7}$ at maximum load versus temperature ( $U$, fig. 6 ) shows a continuous slightly downward course as the test temperature is increased from $-320^{\circ}$ to $+1,500^{\circ} \mathrm{F}$. The curve, $R$, representing the relation between true strain at complete fracture and test temperature indicates deviation from the steady upward trend occurring at temperatures of about $0^{\circ}$ to $300^{\circ} \mathrm{F}$ and $500^{\circ}$ to $700^{\circ} \mathrm{F}$; the conditions are similar to those already described for plastic extension and reduction of area-temperature curves of figure 5 .

\subsection{Relation of Strength to True Strain}

The relation between both the nominal stress and true stress at maximum load and the true strain as affected by temperature is shown by the curves $U$ and $U_{T}$, respectively, in figure 7 . The two curves are somewhat similar in shape, and discontinuities are evident for values of strains within the ranges of about 0.25 to 0.3 and 0.32 to 0.37 . Irregularities are also observed in the course of the curve of true stress at fracture versus true strain (fig. 8). The form of this curve is affected by the variations in the degree of necking and the rim formation accompanying deformation from beginning to complete fracture (figs. 9 and 10) of the specimens tested at the different

7 True strain is defined as the natural logarithm of the ratio of the initial crosssectional area $\left(A_{0}\right)$ of the specimen to its current cross-sectional area $(A)$ 

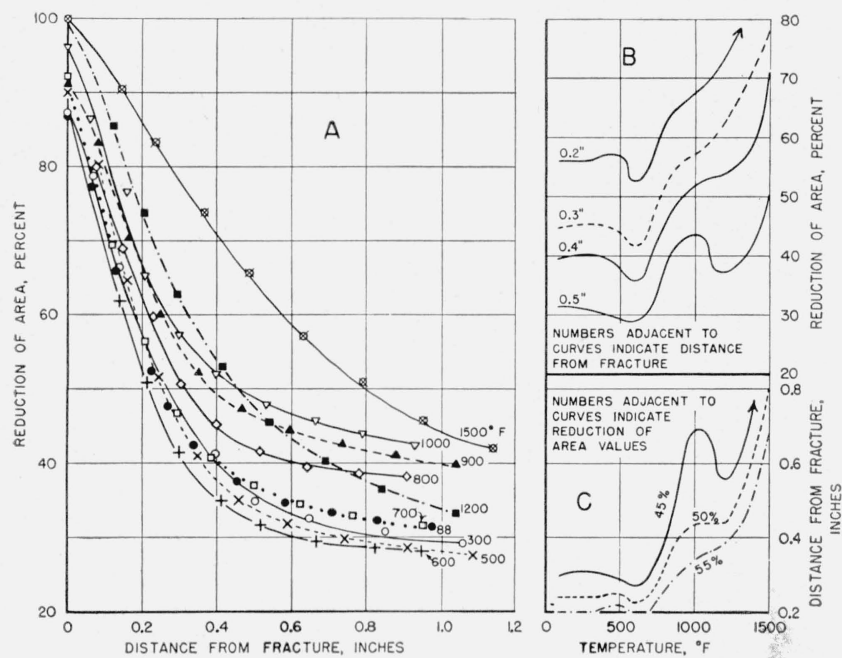

FIGURE 11. Effect of test temperature on the necking characteristic of high-purity nickel specimens fractured in tension.

test temperatures. In the plastic deformation range from maximum load to complete fracture, all the specimens contracted locally, but the contour of the neck varied with the temperature (fig. 11). In certain specimens $\left(600^{\circ} \mathrm{F}\right)$, the necking was confined principally to the region of complete fracture, whereas other specimens $\left(1,500^{\circ} \mathrm{F}\right)$ contracted more uniformly throughout the entire gage length.

An indication of the reproducibility of the strength and ductility values at room temperature and at $+212^{\circ} \mathrm{F}$ for the two bars processed alike from the same heat is given by the results summarized in table 1. Although the two series of tests were made at different times, by different operators, and the specimens were prepared from different bars $(B$ and $C)$, the respective values for strength and ductility agreed closely.

Some of the irregularities observed in the temperature-tensile-properties curves can be partly attributed to metallurgical changes in the nickel. Strain aging occurred in the specimens tested in the temperature range of about $80^{\circ}$ to $300^{\circ} \mathrm{F}$ and attained a maximum in the upper part of this range. The temperature and degree of strain aging are affected by the strain rate and by the purity of the nickel

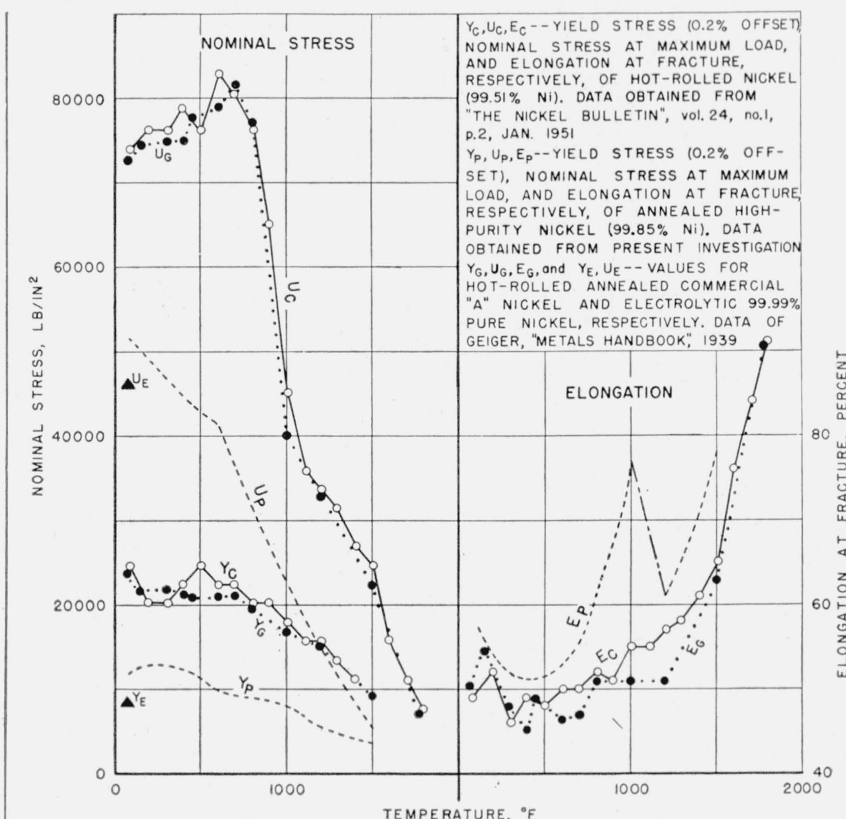

Figure 12. Tensile properties of nickel, varying in purity, as affected by temperature.

(fig. 12). A change in the magnetic properties of high-purity nickel (Curie point) occurs at a temperature of about $665^{\circ} \mathrm{F} .{ }^{8}$ The present results also show certain distinct and abnormal changes in some tensile properties of specimens tested in the temperature range of about $500^{\circ}$ to $700^{\circ} \mathrm{F}$. This range is appreciably below that of recrystallization, and an examination of the microstructure of specimens fractured at $1,000^{\circ} \mathrm{F}$ or below showed no evidence of recovery (fig. $13, A, B, C$, and $D$ ); the hardness test made on the specimen after fracturing at $1,000^{\circ} \mathrm{F}$ indicated that some recovery (softening) occurred at this temperature (fig. 14). However, recrystallization was evident in the specimen tested at $1,200^{\circ} \mathrm{F}$ (fig. $13, E$ ), and recrystallization and some grain growth occurred in the specimen fractured at $1,500^{\circ}$ $\mathrm{F}$ (fig. 13, $F^{\prime}$ ). Some twins are evident in the recrystallized structure of the specimen tested at $1,500^{\circ} \mathrm{F}$.

8 E. M. Wise, Properties of nickel and nickel alloys, Metals Handbook, p. 1046 (1948).

TABLE 1. Tensile properties at room temperature and $212^{\circ} \mathrm{F}$ of the two bars of high-purity nickel used

\begin{tabular}{|c|c|c|c|c|c|c|c|c|c|c|c|}
\hline \multirow{3}{*}{ Bar designation } & \multirow{3}{*}{$\begin{array}{l}\text { Temper- } \\
\text { ature of } \\
\text { test }\end{array}$} & \multirow{3}{*}{$\begin{array}{c}\text { Yield } \\
\text { strength a }\end{array}$} & \multirow{3}{*}{$\begin{array}{l}\text { Tensile } \\
\text { strength }\end{array}$} & \multicolumn{3}{|c|}{ Maximum load } & \multicolumn{5}{|c|}{ Fracture } \\
\hline & & & & \multirow[b]{2}{*}{$\begin{array}{l}\text { True } \\
\text { stress }\end{array}$} & \multirow[b]{2}{*}{$\begin{array}{l}\text { Exten- } \\
\text { sion }\end{array}$} & \multirow[b]{2}{*}{$\begin{array}{l}\text { Reduc- } \\
\text { tion of } \\
\text { area }\end{array}$} & \multicolumn{2}{|c|}{ Beginning } & \multicolumn{3}{|c|}{ Complete } \\
\hline & & & & & & & $\begin{array}{l}\text { True } \\
\text { stress }\end{array}$ & $\begin{array}{l}\text { Reduc- } \\
\text { tion of } \\
\text { area }\end{array}$ & $\begin{array}{l}\text { True } \\
\text { stress }\end{array}$ & $\begin{array}{l}\text { Exten- } \\
\text { sion }\end{array}$ & $\begin{array}{l}\text { Reduc- } \\
\text { tion of } \\
\text { area }\end{array}$ \\
\hline $\begin{array}{l}\mathrm{B} \\
\mathrm{C} \\
\mathrm{B} \\
\mathrm{B} \\
\mathrm{C}\end{array}$ & $\begin{array}{r}\circ F \\
75 \\
88 \\
212 \\
212\end{array}$ & $\begin{array}{c}\text { 1,000 } \\
l \text { lb/in. } \\
12.5 \\
12.5 \\
12.5 \\
12.0\end{array}$ & $\begin{array}{c}\text { 1,000 } \\
l, / \text { in } .^{2} \\
52.7 \\
51.6 \\
48.4 \\
48.3\end{array}$ & $\begin{array}{c}\text { 1,000 } \\
l b / / \text { in. }^{2} \\
76.7 \\
72.3 \\
69.2 \\
68.5\end{array}$ & $\begin{array}{l}\% \\
45 \\
41 \\
43 \\
42\end{array}$ & $\begin{array}{l}\% \\
31 \\
29 \\
31 \\
30\end{array}$ & $\begin{array}{l}\text { 1,000 } \\
l, / \text { inn. } \\
145.5 \\
145.3 \\
128.1 \\
130.0\end{array}$ & $\begin{array}{l}\% \\
79 \\
80 \\
79 \\
79\end{array}$ & $\begin{array}{c}1,000 \\
l b / \mathrm{in}^{2} \\
278.6 \\
222.8 \\
2210.6 \\
224.2\end{array}$ & $\begin{array}{l}\% \\
56 \\
56 \\
57 \\
57\end{array}$ & $\begin{array}{l}7 \\
89 \\
87 \\
87 \\
88\end{array}$ \\
\hline
\end{tabular}

a $0.2 \%$ offset. 



FIGURE 13. Structure at fracture of high-purity nickel specimens tested in tension at different temperatures Longitudinal section near axis of specimens. (Etched with 6 parts nitric (concentrated), 4 parts glacial acetic acids). $\times 100 . \quad$ A, $88^{\circ} \mathrm{F} ; \mathrm{B}$,
$600^{\circ} \mathrm{F} ; \mathrm{C}, 800^{\circ} \mathrm{F} ; \mathrm{D}, 1,000^{\circ} \mathrm{F} ; \mathrm{E}, 1,200^{\circ} \mathrm{F} ; \mathrm{F}, 1,500^{\circ} \mathrm{F}$.

\subsection{Relation of Plastic Deformation to Hardness}

The effect of plastic deformation and recovery at different temperatures on hardness at room temperature of the fractured specimens is given by the results plotted in figures 14 and 15 . The general trend was for the hardness at room temperature to decrease slightly with increase in distance from the fracture (decrease in reduction of area) for each specimen fractured in the range of $88^{\circ}$ to $1,000^{\circ} \mathrm{F}$. The hardness measurements indicate that the work-hardening and recovery charactersstics were quite similar for specimens tested in the range from $88^{\circ}$ to $700^{\circ} \mathrm{F}$, and the degrees of recovery increased (hardness decreased) with increase in test temperature from $800^{\circ}$ to $1,000^{\circ} \mathrm{F}$. Appreciable recovery occurred in the specimens tested at $1,200^{\circ}$ and $1,500^{\circ} \mathrm{F}$. This is to be expected, because, as previously pointed out, both temperatures are sufficiently high for recrystallization of the plastically deformed metal. The lower hardness values for the specimen tested at $1,500^{\circ} \mathrm{F}$ can be attributed to the higher degree of recovery and increase in grain size. The hardness of the specimen fractured at $1,500^{\circ} \mathrm{F}$ decreased with an increase in plastic deformation or with decrease in distance from the fracture end. Furthermore, the hardness, measured at room temperature, of the specimen fractured at $1,200^{\circ} \mathrm{F}$ did not materially change over the gage length corresponding to a range in reduction of area from 35 to 75 percent 


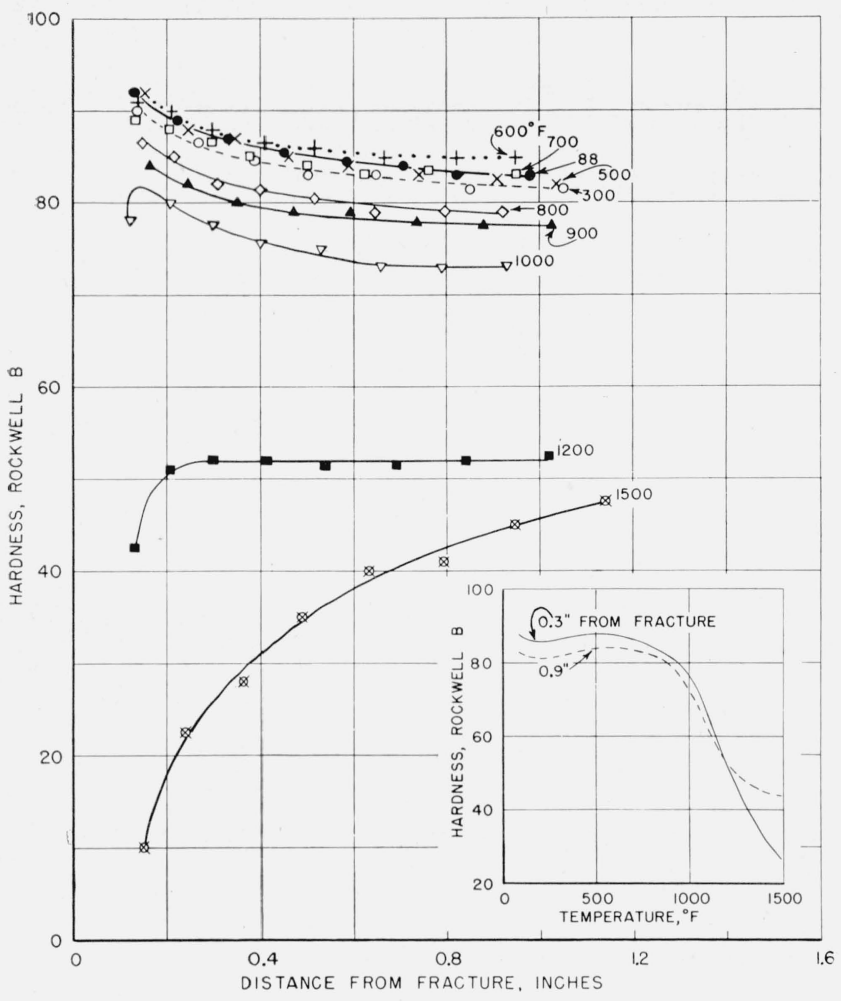

Figure 14. Relation of hardness at room temperature to distance from fracture of high-purity nickel specimens tested in tension at different temperatures.

Hardness of the annealed nickel before testing in tension was Rockwell B 32 .

(1.0 to 0.2 in., respectively, from fracture end). The hardness of this plastically deformed specimen (Rockwell B 52), however, was appreciably higher than that of the annealed nickel (Rockwell B 32). Hardness induced by plastic deformation was even evident in a part of the recrystallized specimen that was deformed at $1,500^{\circ} \dot{\mathrm{F}}$. However, above 65 -percent reduction of area its hardness was either equivalent to or below that of the originally annealed nickel.

\section{Summary}

Tensile tests were made at temperatures ranging from $-320^{\circ}$ to $+1,500^{\circ} \mathrm{F}$ on specimens containing 99.85 percent of nickel in the annealed condition. The results are summarized in the figures given in the report.

The general trends were for the yield and tensile strengths and the ductility at maximum load to de-

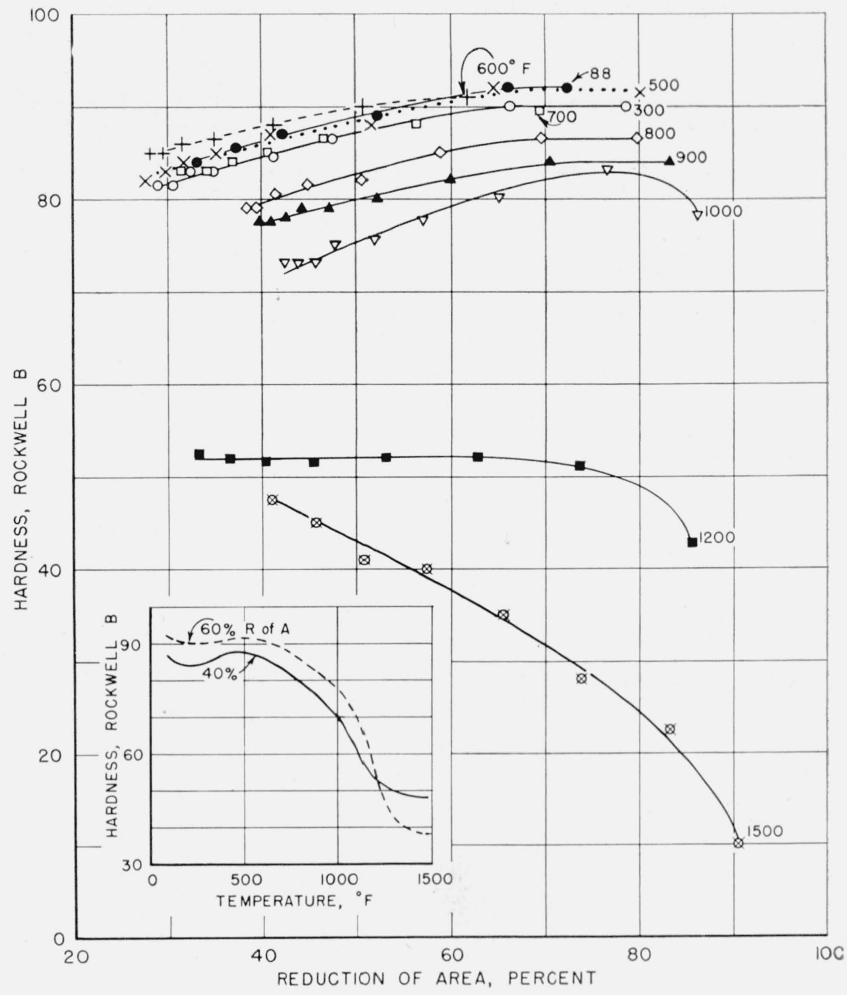

FIGURE 15. Effect of deforming high-purity nickel in tension at different temperatures on the hardness at room temperature.

Hardness of the annealed nickel before testing in tension was Rockwell B 32.

crease, and the reduction of area (at complete iracture) to increase with an increase in test temperature. The elongation at complete iracture attained a minimum at about $500^{\circ} \mathrm{F}$. However, irregularities were observed in the usual trends of some of the tensile properties-temperature relations at test temperatures in the ranges of about $80^{\circ}$ to $300^{\circ} \mathrm{F}$ and $500^{\circ}$ to $700^{\circ} \mathrm{F}$. The evidence indicated that strain aging occurred in the range $80^{\circ}$ to $300^{\circ} \mathrm{F}$ and that recrystallization and recovery predominated in specimens fractured at $1,200^{\circ}$ or $1,500^{\circ} \mathrm{F}$.

The authors gratefully acknowledge the assistance of C. R. Johnson and J. H. Darr in making the tension tests at elevated temperatures and of $\mathrm{G}$. W. Geil and N. L. Carwile in making the tests at sub-zero temperatures.

Washington, February 5, 1952. 